\title{
The NW Potiguar Basin seismic zone: spatio-temporal evolution, stress regime and implications for moderate-size earthquake occurrence
}

José Augusto Silva da Fonsêca, Federal University of Rio Grande do Norte Joaquim Mendes Ferreira, Federal University of Rio Grande do Norte

Aderson Farias do Nascimento, Federal University of Rio Grande do Norte

Francisco Hilário Rego Bezerra, Federal University of Rio Grande do Norte

Heleno Carlos de Lima Neto, Federal University of Rio Grande do Norte

Eduardo Alexandre de Menezes, Federal University of Rio Grande do Norte

Copyright 2021, SBGf - Sociedade Brasileira de Geofísica.

This paper was prepared for presentation during the $17^{\text {th }}$ International Congress of the Brazilian Geophysical Society held in Rio de Janeiro, Brazil, 8-11 November 2021 (Online Event). Contents of this paper were reviewed by the Technical Committee of the $17^{\text {th }}$ International Congress of the Brazilian Geophysical Society and do not necessarily represent any position

of the SBGf, its officers or members. Electronic reproduction or storage of any part of this paper for commercial purposes without the written consent of the Brazilian Geophysical Society is prohibited.

Away from border plate regions, earthquakes are less frequent and smaller-scaled in magnitude, yet as seismic energy attenuation is lower, moderate-size magnitude intraplate earthquakes can pose significant hazard. However, its source mechanisms remain with no compliance once surface features have not been easily associated with seismogenic structures. Therefore, assessing the stress field in mid-plate areas is important to better understand the earthquake generating mechanisms. On November 20, 1980, NE Brazil was hit by a $5.2 \mathrm{mb}$ earthquake in NW Potiguar Basin, which was felt up to $600 \mathrm{~km}$ from the epicentral zone, causing collapse and damage of buildings in the epicentral area. The entire activity, including the related aftershocks, lasted for more than two years. After a quiescent period which lasted until 1998, seismicity was noticed again in 2017, when a seismic network composed of five short period triaxial sensors and one broadband triaxial sensor was deployed in the area and operated continuously for 9 months. From the 2017 deployment, we analyzed 241 earthquakes, estimated the stress regime and the occurrence of moderate-size earthquakes in the light of previous works. Our results reveal seismically defined faults using high-precision double difference hypocentral relocation methods concentrated in NW-SE- and NE-SW-trending clusters. In one of these clusters the hypocentral distribution can be interpreted using the faulting intersection for intraplate earthquakes to explain why moderate size earthquakes occur in the study region. In addition, another cluster presented a seismically defined fault vertically segmented with a clear spatiotemporal evolution and occurrence during almost entire activity in a very short period, which suggests energy build-up and rapid release between its segments. Composite focal mechanisms determined for three clusters indicate a predominance of strike-slip faulting with a sinistral movement. The estimation of the main stress directions based on focal mechanism data available since 1980 confirms the superposition of local and regional stresses, with SHmax axis subparallel to the continental equatorial margin. 